\title{
Fifty six continence advisers, one peripatetic teacher
}

\author{
C Hall, C M Castleden, G J Grove
}

\begin{abstract}
The increasing demand for the services of a continence nurse led to a novel plan to combat such demand in Leicestershire. The district nursing service seconded a nurse to be trained as an adviser and then to return to the community to set up continence clinics in each health centre. The adviser selected nurses to run these clinics and taught them the skills required to do so. She also carried her own caseload.

One hundred and one patients were seen in the clinics in the first year, of whom $\mathbf{3 0}$ were cured. In a further one third continence was greatly improved, and the remainder benefited from advice and consultation. The adviser has worked in only six health centres but has had a greater impact on dealing with incontinence than a series of lectures and seminars for district nurses over many years had had.
\end{abstract}

\section{Introduction}

After the health authorities and the United Kingdom Central Committee for Nursing recognised the importance of treating and managing incontinent patients there was an enormous expansion in the number of posts for continence nurse advisers. Although there was an established continence service in Leicestershire run by a consultant geriatrician and a continence nurse adviser, they could not meet the increasing demand. Since most of the referrals came from the community, mainly initiated by community nurses, it seemed reasonable to teach these nurses to manage incontinence correctly rather than refer so many of their patients to a specialist adviser. A district nursing sister was seconded initially to be trained as a continence nurse adviser and then to teach the district nurses to manage this condition in health centres throughout the district. As there have been no reports of similar schemes we describe setting up such a project and its initial results.

\section{Methods}

Training the district nurse - The nurse completed the English National Board 978 course and then joined a continence clinic at a hospital,' working alongside the specialist continence adviser and a consultant geriatrician. She became proficient in carrying out the assessment, clinical examination, and urodynamic investigation and in starting treatment for incontinent patients. After four weeks she returned to the community but had open access to the hospital, the consultant, and the specialist nurse adviser, meeting them weekly. She also ran a weekly session in which she carried out urodynamic investigations for her own patients.

Role of continence adviser and primary health care team-There are 14 centres of management within the central community unit of the district, including a night nursing service and a school nursing service. It was decided that the trained community nurse would spend about eight weeks in each centre and would inform the managers, nursing team, and doctors before arriving. The nurse was to help selected nurses (average number two in each health centre) to assess the type and severity of incontinence and establish treatments. These resource link nurses then ran the continence clinics after the adviser had left the health centre.

The continence adviser had a small clinical caseload to give credibility to what was being taught. In each centre the adviser held tutorials and small group discussions at first, which were followed by visits to the patient's home with their district nurse. Clinics were also held in the health centre for incontinent patients. All patients who collected incontinence garments from the health centres were offered attendance at such clinics. Cooperation with general practitioners was vital to the success of the project since a two way referral was an essential part.

The clinics were held according to need. Clients were given appointments at 30 minute intervals, which allowed time for assessment, physical examination, urineanalysis, teaching, and demonstration to ensure that they understood the management programmes, products, and appliances. Follow up appointments usually lasted about 15 minutes.

Research was included in the job description, and a study of why indwelling catheters were used as the preferred method of managing incontinence was carried out. Patients' emotions and feelings and the physical and practical aspects for both patients and carers before and after the use of a catheter were examined.

\section{Results}

Clinics have been set up in six centres, and 10 district nurses have been specially trained to manage them. There are 150 staff of all grades, including school nurses, health visitors, enrolled nurses, and auxilliaries, who have had less training than the nurses managing the clinics, but nevertheless can now help to manage patients with incontinence.

In the first year 101 patients were seen (mean age 40 1 years, range 36-80), 94 of whom were women. Each patient attended at least twice. Two thirds of the patients were known to the primary health care team before the clinics were set up. Treatment is continuing for these patients, but the results show that $\mathbf{3 0}$ were completely dry and therefore regarded as cured (table I). Twenty nine either did not respond to treatment or were not suitable for treatment and therefore received advice on appliances and garments.

The adviser managed 143 patients (mean age 68, range 16-93) at home in the first year without the help of the clinics run by the resource link nurses. These patients were too frail to attend the clinics or had been referred to the adviser by the hospital; 107 were women. Many (50) required advice on better appliances, pads, 
TABLE I - Diagnosis, management, and outcome for 101 patients with continence seen only by the community nurses (figures are numbers of patients)

\begin{tabular}{llrrr}
\hline \multirow{2}{*}{$\begin{array}{l}\text { Primary reason } \\
\text { for incontinence }\end{array}$} & Treatment & Cured & Improved & Other $^{\star}$ \\
\cline { 3 - 5 } & & 10 & 11 & 17 \\
\hline (a) Weak pelvic floor $(n=38)$ & Pelvic floor exercises & 8 & 12 & 2 \\
(b) Detrusor instability $(\mathbf{n}=22)$ & Habit retraining & 5 & 6 & 2 \\
(c) Mixed $(\mathbf{a})$ and $(\mathrm{b})(\mathrm{n}=13)$ & (a) and $(\mathrm{b})$ & 4 & 0 & 0 \\
(d) Oestrogen deficiency $(\mathbf{n}=4)$ & Hormone replacement & 3 & 7 & 14 \\
(e) Others $(\mathrm{n}=24)$ & & & & \\
\hline
\end{tabular}

^Treatment only recently started; no response; referred to hospital; managed with appliances.

tIncludes faecal incontinence, postprostatectomy incontinence, cancer/fistula, and fractured pelvis.

TABLE II-Principal diagnosis, management, and outcome for 143 patients treated by the community continence adviser (figures are numbers of patients)

\begin{tabular}{lrrr}
\hline & \multicolumn{3}{c}{ Outcome } \\
\cline { 2 - 4 } Diagnosis & Cured & Improved & Other \\
\hline Bladder instability $(\mathrm{n}=45)$ & 20 & 17 & 8 \\
Urethral sphincter incompetence $(\mathrm{n}=44)$ & 8 & 9 & 27 \\
Hormonel deficiency $(\mathrm{n}=7)$ & 2 & 3 & 2 \\
Others $\dagger(\mathrm{n}=47)$ & 14 & 12 & 21 \\
\hline
\end{tabular}

^Advised on appliances; no improvement; continuing treatment; referred to hospital.

tIncludes immobility (35) or confusion (26) as the primary factor, postIncludes immobility (35) or confusion (26) as the primary factor, post-
prostatectomy incontinence (14), diuretics (10), and urinary tract infection prostatectomy incontinence (14), diuretics (10), and
(nine). Some patients had more than one condition.

or toileting regimens, but 44 became completely dry. Sixteen were referred to the hospital, and 39 remained under the adviser's care at the end of the year (table II).

\section{Discussion}

The value of the nurse in a continence service has already been shown, ${ }^{2}$ and the increasing demands on our service confirms this. The results show that many incontinent patients may be successfully treated by specialist nurses in the community and do not need to be referred to hospital. Indeed, our results were similar to those recently published from a continence clinic based in hospital. ${ }^{3}$ Providing nursing clinics in the community can therefore restrict hospital referrals to patients whose treatment has failed, those with difficult diagnoses, or those who require surgery. The results also suggested a different role for many of the existing continence advisers.

There were many advantages to carrying out this service in a health centre. Firstly, it allowed formal and informal learning to take place by staff in the health centres, including general practitioners and all nursing personnel. Secondly, domestic and secretarial staff benefited from such learning as patients often talked to them and asked them for advice. Thirdly, it was possible to carry out joint home visits with the community nurses. Fourthly, the specialist nurse was considered part of the nursing team and was welcomed in the health centres as an adviser. Finally, it was also possible to see how receptive staff had been to the teaching, what motivation was required, and to evaluate the service first hand.

The community continence adviser retained links with the physiotherapist and occupational therapist and medical aid departments. She attended regional sundries subgroup meetings to discuss the supplies contract and evaluated products on the contract. After leaving each centre it was necessary for the adviser to maintain contact to reinforce, redirect, and reteach management of incontinence.

Successful treatment of incontinence cannot be directly measured by the numbers of who are cured or who manage it more successfully. One important aspect of treatment was to allow clients to talk about their problems to a sympathetic informed listener. Although no figures are available, the number of patients being referred to hospital has decreased and the suitability of referral has greatly improved in areas where the scheme has been in place compared with areas it has not yet reached. Recently the community continence adviser has extended her work to give information and advice to small groups of officers in charge of residential homes both in the local authority and in the private sector. Finally, once staff in all the centres have been taught and basic good management for incontinence is in practice the next step will be to design programmes to prevent incontinence in groups of people who are most vulnerable to it.

1 Castleden CM, Duffin HM, Asher MJ. Clinical and urodynamic studies in 100 elderly incontinent patients. $\mathrm{Br}$ Med $\mathcal{F}$ 1981;282:1103-5.

2 Shepherd AM, Blannin JP, Smart ME. In: Mandelstam D, ed. The role of the nurse in incontinence and its management. London: Croom Helm, 1980:135-55.

3 Castleden CM, Duffin HM, Asher MJ, Yeomanson CW. Factors influencing outcome in elderly patients with urinary incontinence and detrusor instability. Age Ageing 1985; 14:303-7.

(Accepted 19 fuly 1988)
The following statement was agreed by the International Committee of Medical Fournal Editors at its 1988 meeting in Bethesda, Maryland. The committee would welcome comments about the statement.

\section{Editorial freedom}

\section{International Committee of Medical Journal Editors}

Medical journal owners and editors have a common endeavour, the publishing of a reliable and readable journal, produced with due respect for the stated aims of the journal and for costs. The functions of owners and editors, however, are different. Owners have the right to appoint and dismiss editors and to make important business decisions, in which editors should be involved to the fullest extent possible.

Editors must have full authority for determining the editorial content of the journal. This concept of editorial freedom should be resolutely defended by editors even to the extent of placing their positions at stake. To secure this freedom in practice, the editor should have direct access to the highest level of ownership, not only to a delegated manager.

Medical journal editors should have a contract that clearly states the editor's rights and duties in addition to the general terms of the appointment and defines mechanisms for resolving conflict.
An independent editorial advisory board may be useful in helping the editor establish and maintain editorial policy.

All editors and editors' organisations have the obligation to support the concept of editorial freedom and to draw major transgressions of such freedom to the attention of the international medical community.

Members of the committee are: Edward J Huth (Annals of Internal Medicine), Kathleen King (Medical fournal of Australia), Stephen Lock (British Medical fournal), George D Lundberg (Fournal of the American Medical Association), Ian Munro (Lancet), Magne Nylenna (Tidsskrift for den Norske Laegeforening), Arnold S Relman (New England fournal of Medicine), Povl Riis (Fournal of the Danish Medical Association), Richard Robinson (New Zealand Medical fournal), Bruse P Squires (Canadian Medical Association fournal), Ilkka Vartiovaara (Finnish Medical fournal), Malcolm S M Watts (Western Medical fournal).

Correspondence to: Dr Huth or Dr Lock. 